\title{
Tensile Properties and Press Formability of a Mg-9Li-1Y Alloy Sheet*
}

\author{
Hirohiko Takuda $^{1}$, Shiomi Kikuchi ${ }^{2}$, Noriyuki Yoshida ${ }^{1}$ and Haruo Okahara ${ }^{3}$ \\ ${ }^{1}$ Department of Energy Science and Technology, Kyoto University, Kyoto 606-8501, Japan \\ ${ }^{2}$ Department of Materials Science, The University of Shiga Prefecture, Hikone 522-8533, Japan \\ ${ }^{3}$ Development Section, Kasatani Corp., Osaka 532-0036, Japan
}

The formability of an experimentally produced $\mathrm{Mg}-9 \% \mathrm{Li}-1 \% \mathrm{Y}$ alloy sheet with a thickness of 0.6 mm is investigated. Uniaxial tension tests and some fundamental press-forming tests, such as stretching, deep-drawing, and bore-expanding tests, are carried out at room temperature. The sheet has sufficiently high ductility under uniaxial tension. However, ductility decreases with an increase in strain rate. Even at room temperature, the flow stress is also sensitive to the strain rate. The stress and the work-hardening rate increase with the strain rate. The strain rate sensitivity affects the formability in press forming. The critical punch stroke in the stretching test decreases with an increase in punch speed. However, the limit drawing ratio increases with the punch speed due to the increase in the work-hardening rate. The Erichsen value is estimated to be $9 \mathrm{~mm}$, and the limit drawing ratio is 2.15 . It may be concluded that the sheet has sufficiently high formability.

(Received February 7, 2003; Accepted August 18, 2003)

Keywords: sheet metal forming, tension test, nonferrous metal (Mg-9Li-1Y), material property, forming limit

\section{Introduction}

The demand for lightweight materials, to reduce car weight, for example, has increased in recent years from the viewpoints of energy saving and environmental preservation. Although aluminium alloy is used for a considerable number of car components, the use of magnesium alloy, which is the lightest structural material, is still limited to a very narrow range of applications.

Magnesium forms a hexagonal close-packed structure and has poor formability at room temperature due to slip planes limited to the base plane alone. However, it is well known that the addition of lithium to magnesium gives rise to a highly workable, body-centered cubic phase. ${ }^{1-3)}$ Magnesiumlithium (Mg-Li) alloys exhibit two phase structures between 5.7 and 11 mass\% Li contents, consisting of the $\alpha$ (hcp) magnesium-rich and $\beta$ (bcc) lithium-rich phases at room temperature. The $\beta$ single phase is present when the $\mathrm{Li}$ content is greater than 11 mass\%. Lithium is lighter than magnesium. Due to their ultralow densities $\mathrm{Mg}$-Li alloys are attractive. Therefore, investigations of alloy design and metallography as well as the mechanical properties of $\mathrm{Mg}-\mathrm{Li}$ alloys have been continuously carried out. ${ }^{1-20)}$ Also, the exhibition of superplastic behaviour in $\mathrm{Mg}$-Li alloys composed of the $(\alpha+\beta)$ phases has been pointed out by Metenier et $a l .{ }^{12)}$ and Kojima et al. ${ }^{13)}$ Higashi et al. ${ }^{18)}$ have clarified that the grain refinement upon the addition of yttrium as a third metal results in extraordinary superplasticity.

Recent research on Mg-Li alloys has been mainly focused on the superplasticity under special conditions, while the plasticity under a variety of deformation conditions has not been sufficiently clarified. In particular, few studies have been performed on the formability of $\mathrm{Mg}$ - $\mathrm{Li}$ thin sheets from a practical point of view. ${ }^{21,22)}$

In this study, the formability of an experimentally produced $\mathrm{Mg}-9 \mathrm{Li}-1 \mathrm{Y}$ alloy sheet is investigated at room temperature in order to examine the possibility of its practical

*This Paper was Originally Published in Japanese in Journal of JSTP 43 (2002) 1077. use. Uniaxial tension and some fundamental press-forming tests are carried out, and the microstructure and texture are observed.

\section{Experimental}

\subsection{Material}

The material used in this study was a $\mathrm{Mg}-9$ mass $\% \mathrm{Li}-$ 1 mass $\%$ Y alloy. The alloy was cast in an induction furnace under an argon atmosphere, and then, iteratively cold-rolled to a thickness of $0.6 \mathrm{~mm}$. The total reduction ratio was about $97 \%$. The alloy sheet was finally annealed at $673 \mathrm{~K}$ for $45 \mathrm{~min}$.

\subsection{Tension tests and press-forming tests}

Uniaxial tension tests were carried out at room temperature. The gauge length and width of the tensile specimens were 50 and $12.5 \mathrm{~mm}$, respectively. The specimens were deformed at a constant cross-head velocity in the range of 0.05 to $300 \mathrm{~mm} \mathrm{~min}^{-1}$, corresponding to an initial strain rate between $1.4 \times 10^{-5}$ and $8.3 \times 10^{-2} \mathrm{~s}^{-1}$.

The stretching test using a hemispherical punch (Erichsen test), cylindrical deep-drawing test, and bore-expanding test were carried out in order to examine the fundamental press formability of the sheet. The diameters of the punches were $20 \mathrm{~mm}$ for the stretching test and $40 \mathrm{~mm}$ for the deep-drawing and bore-expanding tests, respectively. For the deep-drawing tests, four flat-headed punches with corner radii of $2,4,8$, and $12 \mathrm{~mm}$ and a hemispherical punch with a radius of $20 \mathrm{~mm}$ were used. The diameter and the shoulder radius of the die were 42 and $6 \mathrm{~mm}$, respectively. The blank-holder force for each blank was given according to Siebel's equation. ${ }^{23)}$ For the bore-expanding tests a flat-headed punch with a corner radius of $4 \mathrm{~mm}$ and a conical punch with an angle of $60^{\circ}$ were used.

The stretching tests were carried out at three punch speeds of $2.5,10$, and $100 \mathrm{~mm} \mathrm{~min}^{-1}$, the deep-drawing tests at two punch speeds of 10 and $100 \mathrm{~mm} \mathrm{~min}^{-1}$, and the boreexpanding tests at a punch speed of $5 \mathrm{~mm} \mathrm{~min}^{-1}$. In all the tests, a water-insoluble chloric lubricant was used. The 
coefficient of friction between the sheet and tool was measured to be 0.12 by the Bowden-Leben friction test.

\subsection{Metallographic observations}

The microstructure and texture of the sheet were observed before and after the tension tests. The specimens for optical microscopy were prepared by etching with a nitric acid solution. X-ray texture measurements were performed using $\mathrm{CuK}_{\alpha}$ radiation.

\section{Results and Discussion}

\subsection{Microstructure and texture before the tests}

Figure 1 shows the X-ray diffraction pattern of the sheet. Strong (200) and (211) diffraction peaks of the $\beta$ phase and relatively weak diffraction peaks from the $\alpha$ phase are observed. The X-ray diffraction pattern shows that the sheet is composed of $(\alpha+\beta)$ phases, but mainly of the $\beta$ phase.

Figure 2 shows the microstructure of the sheet. Comparatively large grains of the $\beta$ phase and fine grains of the $\alpha$ phase are aligned alternately in parallel with the rolling direction. The grain size of the present sheet containing $\mathrm{Y}$ as the third metal is very small compared with that of the sheet with $\mathrm{Zn}$ as the third metal examined previously. ${ }^{21,22)}$

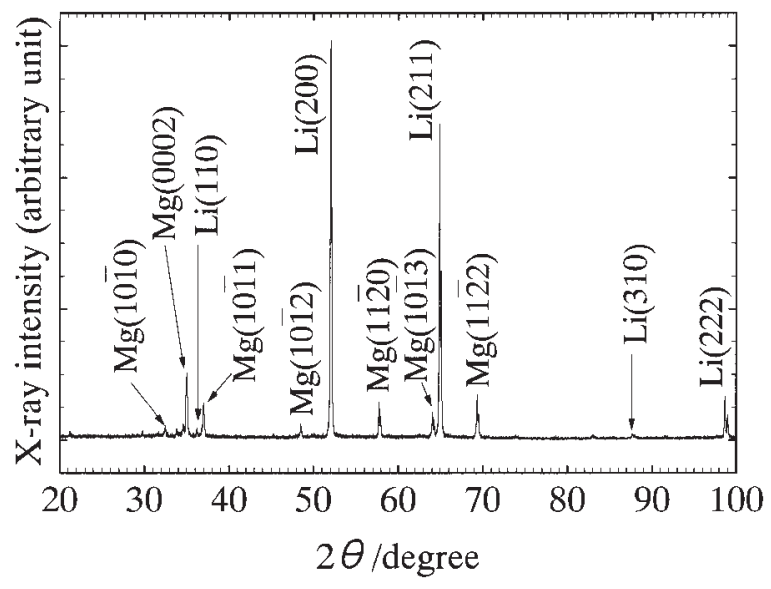

Fig. 1 X-ray diffraction pattern of the Mg-9Li-1Y alloy sheet.

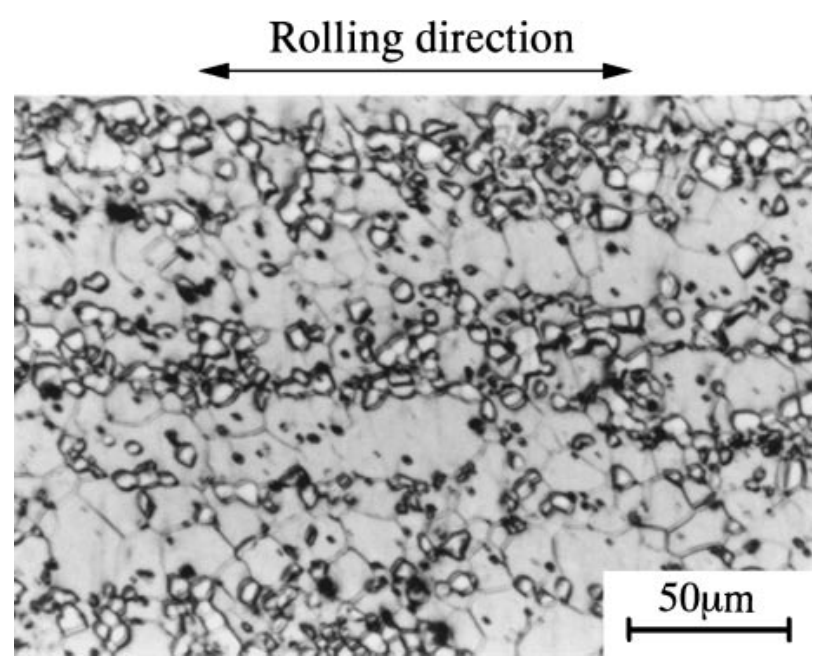

Fig. 2 Microstructure of the sheet.

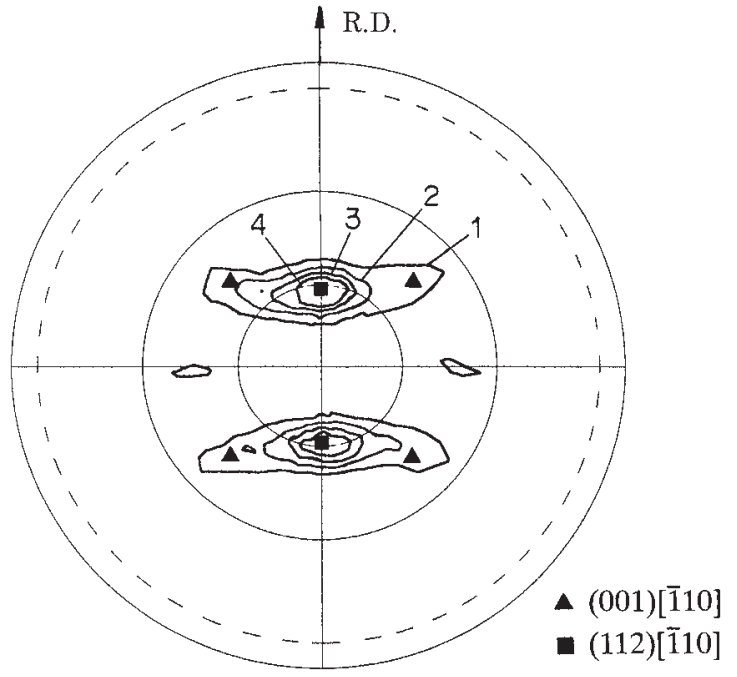

Fig. 3 (110) pole figure of $\beta$ phase of the sheet.

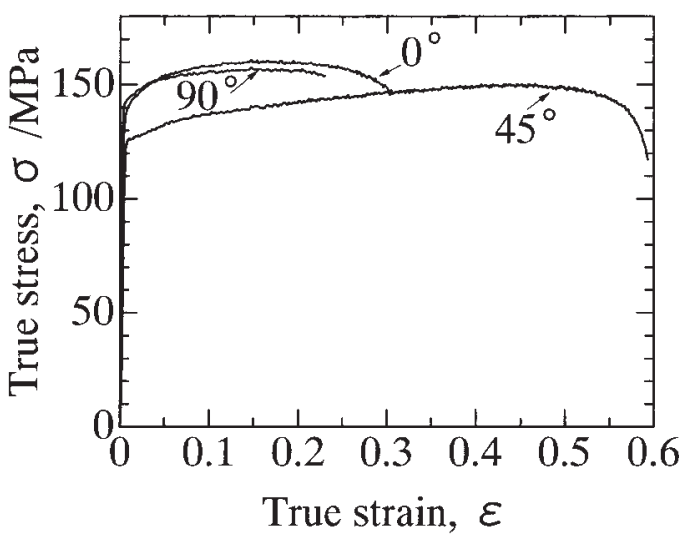

Fig. 4 True stress-strain relationships obtained from uniaxial tension tests in three directions 0,45 , and $90^{\circ}$ with respect to the rolling direction at an initial strain rate of $8.3 \times 10^{-4} \mathrm{~s}^{-1}$.

Figure 3 shows the (110) pole figure for the $\beta$ phase. The main texture components are composed of $(001)[\overline{1} 10]$ and (112)[ㅍ10].

\subsection{Tensile properties}

Figure 4 shows the true stress-strain $(\sigma-\varepsilon)$ curves of the sheet in the directions of 0,45 , and $90^{\circ}$ with respect to the rolling direction, obtained from the uniaxial tension tests under the condition that the initial strain rate is $8.3 \times 10^{-4} \mathrm{~s}^{-1}$. Note that our present curves deviate from the true curves after the occurrence of necking, because the stress and strain were evaluated under the assumption of uniform deformation. The tests were carried out on three samples for each direction. The average values of the tensile properties in each direction for an initial strain rate of $8.3 \times 10^{-4} \mathrm{~s}^{-1}$ are indicated in Table 1 .

Although the elongation in the $90^{\circ}$ direction is shorter than that in the $0^{\circ}$ direction, the true stress-strain curves for the two directions are almost identical, and the anisotropy parameters, $r$ 's, in both directions are much smaller than 1 . On the other hand, the properties in the $45^{\circ}$ direction differ greatly from those in the 0 and $90^{\circ}$ directions. In the $45^{\circ}$ direction, the stress is small, a long elongation of over $70 \%$ is 
Table 1 Tensile properties obtained from uniaxial tension tests at an initial strain rate of $8.3 \times 10^{-4} \mathrm{~s}^{-1}$.

\begin{tabular}{lcccc}
\hline & $0^{\circ}$ & $45^{\circ}$ & $90^{\circ}$ & Mean \\
\hline Proof stress /MPa & 137 & 125 & 140 & 131 \\
Tensile strength /MPa & 147 & 128 & 146 & 137 \\
Elongation /\% & 34.9 & 74.0 & 22.3 & 51.3 \\
Normal anisotropy parameter, $r$ & 0.46 & 1.93 & 0.40 & 1.18
\end{tabular}

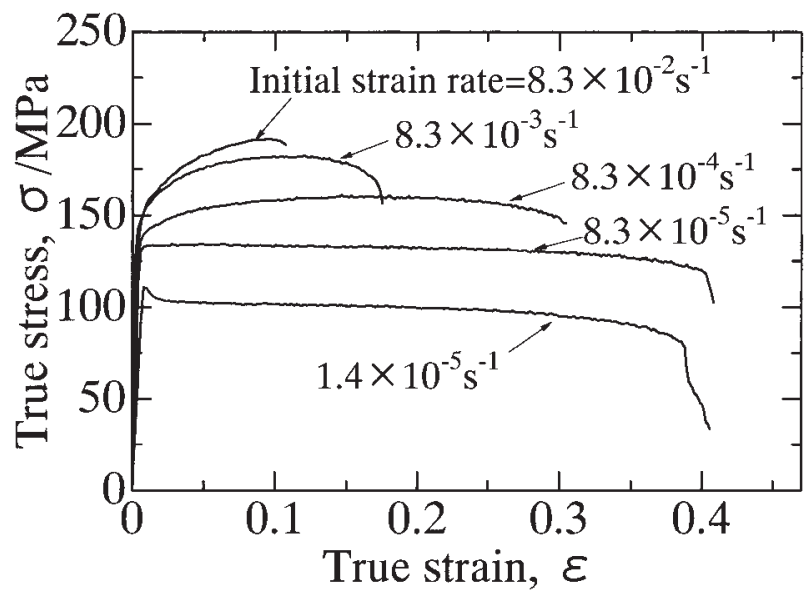

Fig. 5 True stress-strain relationships for various strain rates, obtained from uniaxial tension tests in the rolling direction.

attained, and the $r$-value is high (1.93). The $\Delta r$, which is defined by $\left(r_{0}+r_{90}-2 r_{45}\right) / 2$ and is a measure of the planar anisotropy, is estimated to have a large negative value of -1.50 .

Figure 5 shows the true stress-strain relationships for various initial strain rates, obtained from the uniaxial tension tests in the rolling direction. At comparatively low strain rates, the elongation is long. At the lowest strain rate of $1.4 \times 10^{-5} \mathrm{~s}^{-1}$, the yielding phenomenon and work-softening are observed.

A more notable feature of the sheet is that not only the elongation, but also the flow stress depends on the strain rate even at room temperature. The stress level and workhardening rate increase considerably with strain rate, while the elongation decreases. Figure 6 shows the relationship between the flow stress, $\sigma$, and strain rate, $\dot{\varepsilon}$, at the strain, $\varepsilon$, of 0.1 on a log-log scale. Although it varies depending on the range of strain rate, the average strain rate sensitivity exponent, $m$, is evaluated to be 0.08 . This value is very high for room temperature. It is interesting that the sheet has strain rate sensitivity even at room temperature as if it were at elevated temperatures. This may be due to the low melting point of lithium $(454 \mathrm{~K})$.

Figure 7 shows the relationship between the work-hardening exponent, $n$, and strain rate, when the simple equation $\sigma=F \varepsilon^{n}$ is applied to the true stress-strain relationships in Fig. 5. At low strain rates the $n$-value is negative, namely, work-softening occurs, as shown in Fig. 5. However, the $n$ value increases with increasing strain rate.

There is no obvious change in the microstructure during the tension tests, except that the grains are elongated toward the tensile direction, and that the grain boundaries become indistinct, as illustrated in Fig. 8. This figure shows the

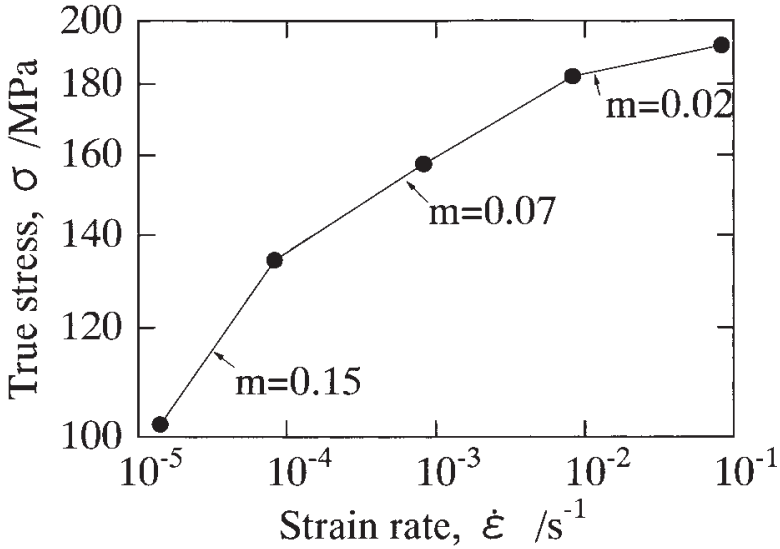

Fig. 6 Relationship between true stress and strain rate on $\log -\log$ scale at a strain of 0.1 .

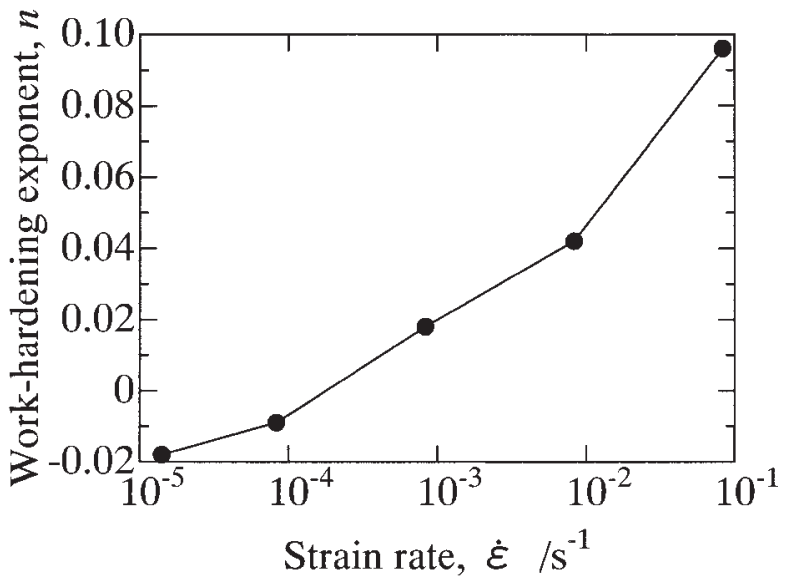

Fig. 7 Relationship between work-hardening exponent and strain rate.

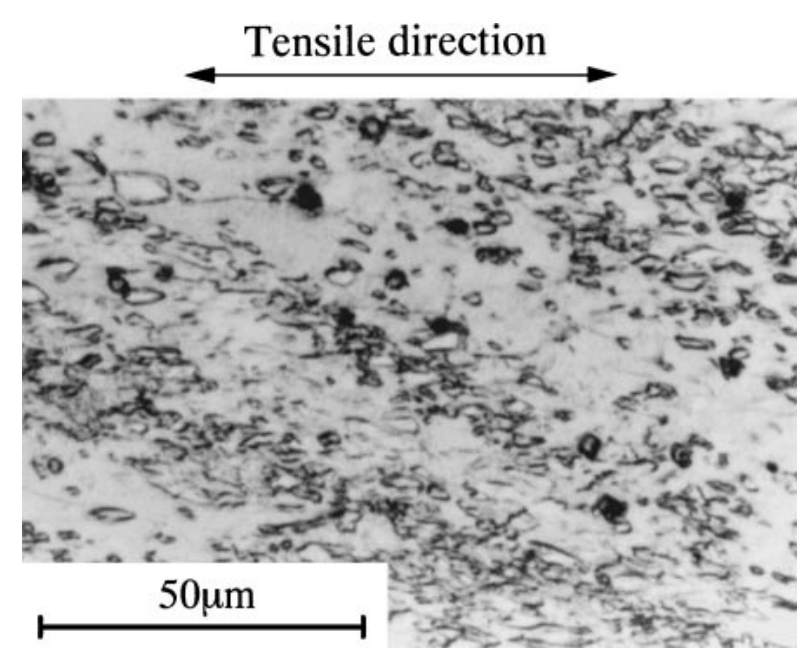

Fig. 8 Microstructure of the sheet after tension test in $45^{\circ}$ direction for an initial strain rate of $8.3 \times 10^{-4} \mathrm{~s}^{-1}$.

microstructure after the tension test in the $45^{\circ}$ direction where the long elongation is obtained (Fig. 4). Almost no change is observed in the X-ray diffraction patterns or the pole figures of the sheet before and after the tension tests, which revealed that the orientations of the texture shown in Fig. 3 are stable. 


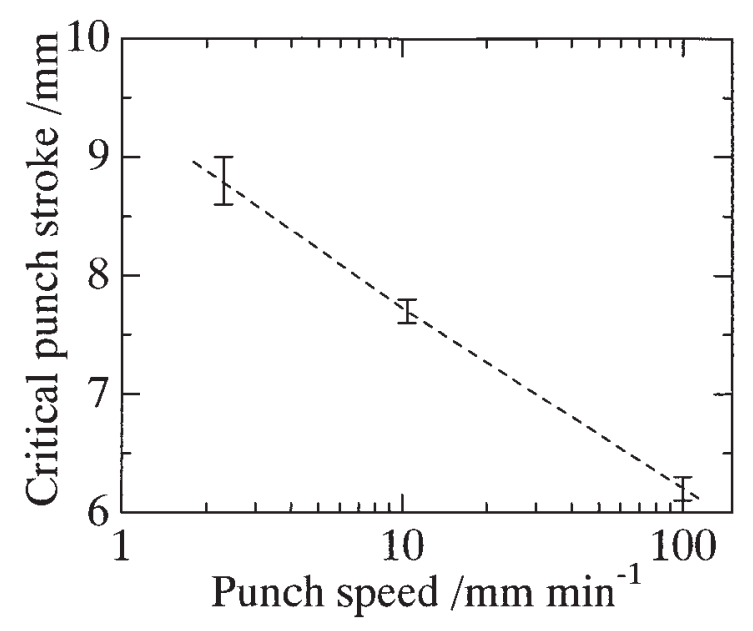

Fig. 9 Relationship between critical punch stroke and punch speed in stretching test.

\subsection{Press formability}

Figure 9 shows the relationship between the critical punch stroke and punch speed in the stretching test. As can be expected from the relationship between the strain rate and ductility in the tension test, the critical stroke decreases with an increase in the punch speed. To obtain a higher forming limit in stretching, the working speed should be low. The Erichsen test is usually carried out under a low punch speed of about $5 \mathrm{~mm} \mathrm{~min}^{-1}$. Therefore, the Erichsen value may be estimated to be 8 to $9 \mathrm{~mm}$.

Figure 10 shows the relationship between the limit drawing ratio, LDR, and the punch corner radius, $r_{\mathrm{p}}$, for two punch speeds, $v_{\mathrm{p}}$. It is notable that the LDR for the higher speed of $100 \mathrm{~mm} \mathrm{~min}^{-1}$ is larger than that for $10 \mathrm{~mm} \mathrm{~min}^{-1}$, in contrast with the forming limit in the stretching test. In this figure the results for the case where the blank holder force is 10 times higher are indicated, and they also show that the forming limit of the sheet in deep drawing is higher for a higher punch speed. In deep drawing, the forming limit usually depends on the localized necking around the punch corner. As shown in the results of the tension tests the workhardening rate is low at low strain rates. Therefore, at a lower

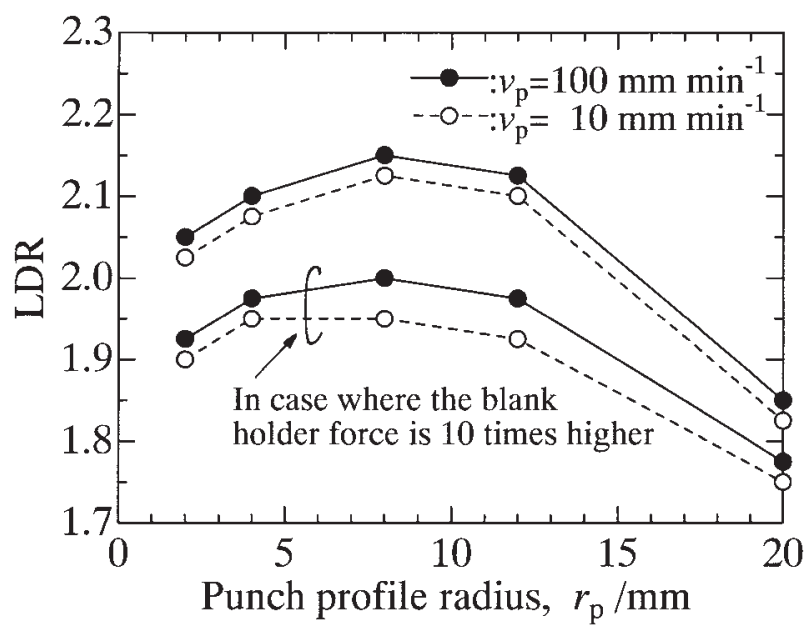

Fig. 10 Relationships between limit drawing ratio and punch profile radius for two punch speeds, $v_{\mathrm{p}}$, of 10 and $100 \mathrm{~mm} \mathrm{~min}^{-1}$. working speed, it is easy for the deformation to be localized around the punch corner. On the contrary, at a higher working speed, the part of the sheet around the punch corner is workhardened, and a higher LDR is obtained.

It is found from Fig. 10 that the sheet has sufficiently high drawability. The LDR is 2.15 for $r_{\mathrm{p}}$ of $8 \mathrm{~mm}$. The influence of the punch corner radius of the flat-headed punch on the forming limit is small, namely, the decrease in the LDR with $r_{\mathrm{p}}$ is small in spite of severe bending at the punch corner. However, the LDR for the hemispherical punch $\left(r_{\mathrm{p}}=20 \mathrm{~mm}\right)$ is considerably smaller than those for the flat-headed punches.

During deep drawing, the so-called ears are formed due to the planar anisotropy. Figure 11 shows a sample of a drawn cup after the deep-drawing test. As can be expected from the large negative value for $\Delta r$, large ears are formed in the $45^{\circ}$ direction with respect to rolling. The earing ratio, $h_{\mathrm{e}}$, is given as $h_{\mathrm{e}}=2\left(h_{\max }-h_{\min }\right) /\left(h_{\max }+h_{\min }\right)$, where $h_{\max }$ and $h_{\min }$ are average values of four maximum and four minimum heights of the drawn cup, respectively. The relationships between the earing and drawing ratios for various punch profile radii are indicated in Fig. 12. The earing ratio is evaluated to be 15 to $20 \%$, which causes a large loss of yield.

Finally, the results of the bore-expanding tests are indicated in Table 2. The bore-expanding ratio, $\lambda$, is evaluated as $\lambda=\left(D_{\mathrm{f}}-D_{0}\right) / D_{0}$, where $D_{\mathrm{f}}$ is the critical diameter of the expanded bore at the time of fracture initiation and $D_{0}$ is the initial bore diameter $(=10 \mathrm{~mm})$. The

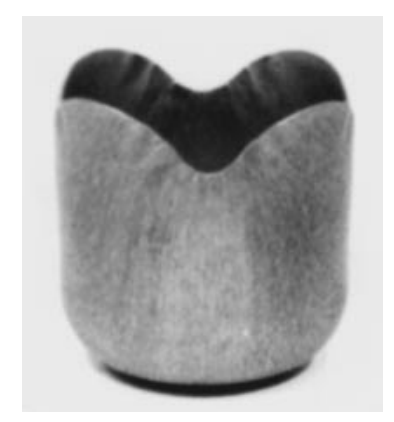

Fig. 11 Drawn cup after deep-drawing test for a drawing ratio of 2.1 and $r_{\mathrm{p}}$ of $12 \mathrm{~mm}$.

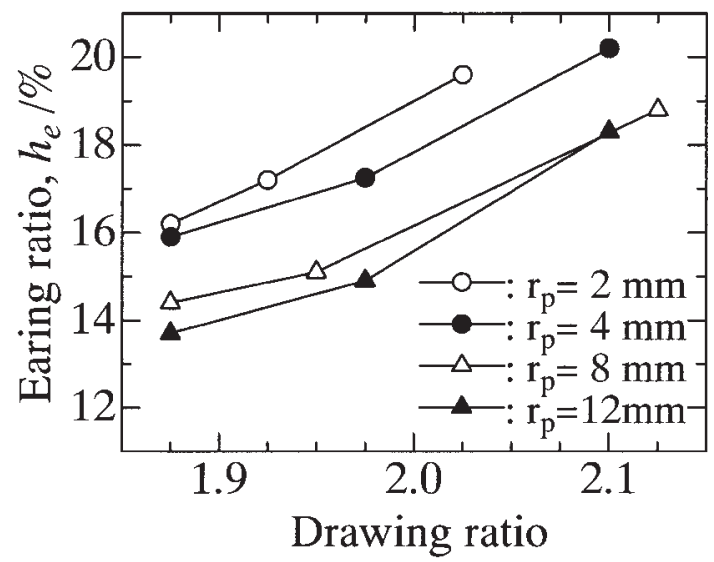

Fig. 12 Relationship between earing ratio and drawing ratio in deepdrawing test. 
Table 2 Bore-expanding ratio, $\lambda$.

\begin{tabular}{ccc}
\hline & Flat-headed punch & Conical-headed punch \\
\hline$\lambda / \%$ & 45 & 80 \\
\hline
\end{tabular}

bore-expanding ratio is $45 \%$ for the flat-headed punch and $80 \%$ for the conical punch, respectively.

\section{Conclusions}

In this study, the formability of an experimentally produced Mg-9Li-1Y alloy thin sheet was investigated. Uniaxial tension tests at various strain rates between $1.4 \times$ $10^{-5}$ and $8.3 \times 10^{-2} \mathrm{~s}^{-1}$ and some fundamental pressforming tests were carried out at room temperature. The results are summarized as follows.

(1) The sheet exhibits sufficiently high ductility at comparatively low strain rates, the average elongation being above $50 \%$ at $8.3 \times 10^{-4} \mathrm{~s}^{-1}$. The sheet has strain rate sensitivity even at room temperature. The flow stress and the workhardening rate increase notably with the strain rate, while the elongation decreases.

(2) The forming limit in stretching depends mainly on the ductility of the sheet. Therefore, the working speed should be low to obtain high stretchability. However, the limit drawing ratio increases with punch speed due to the increase in workhardening rate.

(3) The Erichsen value, limit drawing ratio, and boreexpanding ratio are $9 \mathrm{~mm}, 2.15$, and $80 \%$, respectively, at maximum. It may be concluded that the sheet has sufficiently high formability.

\section{Acknowledgements}

The authors would like to thank Mitsui Mining \& Smelting Co. Ltd for providing the sheet. This study was financially supported by Iketani Science and Technology Foundation and Suzuki Foundation.

\section{REFERENCES}

1) J. H. Jackson, P. D. Frost, A. C. Loonam, L. W. Eastwood and C.H. Lorig: Trans. AIME 185 (1949) 149-168.

2) R. S. Busk, D. L. Leman and J. J. Casey: Trans. AIME 188 (1950) 945951.

3) P. D. Frost, J. G. Kura and L. W. Eastwood: Trans. AIME 188 (1950) 1277-1282.

4) W. E. Freeth and G. V. Raynor: J. Inst. Metals 82 (1953-54) 575-580

5) W. R. D. Jones: J. Inst. Metals 84 (1955-56) 364-378.

6) M. W. Toaz and E. J. Ripling: J. Inst. Metals 85 (1956-57) 137-144.

7) G. V. Raynor and J. R. Kench: J. Inst. Metals 88 (1959-60) 209-216.

8) J. C. McDonald: J. Inst. Metals 97 (1969) 353-362.

9) R. E. Lee and W. J. D. Jones: J. Mater. Sci. 9 (1974) 469-475.

10) M. Sahoo and J. T. N. Atkinson: J. Mater. Sci. 17 (1982) 3564-3574.

11) K. Matsuzawa, T. Koshihara and Y. Kojima: J. Jpn. Inst. Light Metals 39 (1989) 45-51.

12) P. Metenier, G. Gonzales-Doncel, O. A. Ruano, J. Wolfenstine and O. D. Sherby: Mater. Sci. Eng. A 125 (1990) 195-202.

13) Y. Kojima, M. Inoue and O. Tanno: J. Jpn. Inst. Metals 54 (1990) 354355.

14) S. Hori and W. Fujitani: J. Jpn. Inst. Light Metals 40 (1990) 285-289.

15) K. Matsuzawa, T. Koshihara, S. Ochiai and Y. Kojima: J. Jpn. Inst. Light Metals 40 (1990) 659-665.

16) M. Inoue, K. Matsuzawa, O. Tanno, K. Ohuchi and Y. Kojima: J. Jpn. Inst. Light Metals 42 (1992) 67-73.

17) W. Fujitani, N. Furushiro, S. Hori and K. Kumeyama: J. Jpn. Inst. Light Metals 42 (1992) 125-131.

18) K. Higashi, K. Kubota and G. Neite: Proc. Magnesium Alloys and Their Applications, Garmisch Partenkirchen, (1992) 293-300.

19) T. Mukai, K. Ishikawa, Y. Okanda, M. Mabuchi, K. Kubota and K. Higashi: Proc. Light Weight Alloys for Aerospace Applications III, Las Vegas (1995) 483-492.

20) N. Saito, M. Mabuchi, M. Nakanishi, K. Kubota and K. Higashi: Scr. Mater. 36 (1997) 551-555.

21) H. Takuda, S. Kikuchi, T. Tsukada, K. Kubota and N. Hatta: Mater. Sci. Eng. A 271 (1999) 251-256.

22) H. Takuda, T. Enami, K. Kubota and N. Hatta: J. Mater. Process. Technol. 101 (2000) 281-286.

23) E. Siebel: Stahl Eisen 74 (1954) 155-158. 